\title{
AS GRAMÁTICAS MORAIS DA CORRUPÇÃO: APORTES PARA UMA SOCIOLOGIA DO ESCÂNDALO
}

\author{
Edmilson Lopes Júnior ${ }^{1}$
}

\begin{abstract}
RESUMo
Como analisar sociologicamente as práticas de corrupção? Quais aportes teóricos podem ser mobilizados para uma apreensão não essencialista dos escândalos de corrupção? Este artigo aborda estas questões combinando os aportes teóricos da sociologia econômica e da sociologia da moral. A ilustração empírica é dada pelo chamado "Escândalo do Mensalão", acontecimento que marcou a vida política brasileira na última década. Por fim, faço indicações para uma análise sociológica relacional das práticas de corrupção no Brasil.
\end{abstract}

Palavras-chave: Moralidades. Transações. Habilidades. Política. Brasil.

\section{THE MORAL GRAMMARS OF CORRUPTION: THE BASIS FOR A SOCIOLOGY OF SCANDAL}

\begin{abstract}
How does one sociologically analyze the practices of corruption? Which theoretical support may be mobilized for a non-essentialist apprehension of corruption scandals? This article tackles these questions combining the theoretical support

\footnotetext{
${ }^{1}$ Edmilson Lopes Júnior é Professor do Departamento de Ciências Sociais e do Programa de PósGraduação em Ciências Sociais da UFRN. Atua também como docente colaborador do mestrado em Desenvolvimento e Meio Ambiente (PRODEMA). End. eletrônico: edmilsonli23@yahoo.com.
} 
of Economics Sociology and Moral Sociology. The empirical illustration is given through the so called "Mensalão Scandal", a memorable episode in the Brazilian politics in the last decade. Finally, I put forward a sociological analysis of the corruption practices in Brazil.

Keywords: Morality. Transactions. Abilities. Politics. Brazil.

\section{INTRODUÇÃO}

s narrativas a respeito da corrupção estão tão fortemente entranhadas na
vida cotidiana da maioria das sociedades ocidentais que, não raramente, as
investigações produzidas no seio das ciências sociais terminam por contrabandear, com o lustroso verniz do saber douto, apreensões pouco distantes do senso-comum. Embora exista uma farta literatura a respeito da corrupção no nosso campo, em particular na ciência política, avançamos ainda muito pouco na produção de análises substantivas sobre os mundos morais subjacentes às práticas políticas designadas como corruptas. Este ensaio, ancorado em algumas referências empíricas, é uma tentativa de apontar (e aportar) alguns elementos teóricos à análise da corrupção no Brasil.

Não por acaso, a corrupção, como sói ocorrer também com o crime organizado, serve de referente para algumas das mais criativas e escatológicas fantasias contemporâneas. Há, inegavelmente, uma "fala da corrupção" que, assim como a "fala do crime" na instigante e criativa análise da antropóloga Teresa Pires do Rio Caldeira a respeito da violência e segregação urbana, estrutura, ordena e fornece sentido para a apreensão dos fatos e instituições da esfera política. Mesmo se crime e corrupção, na maioria das leituras sociais, tanto dos "bem pensantes" (jornalistas e cientistas sociais) quanto do restante das pessoas nas suas interações do dia a dia, sejam percebidos como irmãos siameses, os eventos que os identificam traduzem níveis radicalmente distintos de rupturas sociais. Assim, embora tenha sentido a afirmação de que a experiência do crime "rompe significado e desorganiza o mundo" (CALDEIRA, 2000, p. 28), o grau de desorganização provocado pela corrupção é bem menos evidente.

Em realidade, talvez se possa afirmar exatamente o contrário: a corrupção "organiza o mundo", fornece referentes para a elaboração de sentidos do mundo. E essa "organização" ocorre já nos seus eventos. E, mais do que as práticas e transações classificadas como "criminosas", as práticas de corrupção 
expressam mundos morais. E estes são fortemente mobilizados não apenas nas narrativas ordinárias das pessoas, mas também nos discursos dos atores revelados contemporaneamente pelos midiáticos "escândalos de corrupção" (sejam eles "corruptos" ou denunciantes de atos de corrupção).

Passível de ter uma definição dicionarizada amplamente aceita, quase fora de qualquer questionamento, a corrupção, para usar aqui um lugar-comum que vai se tornando tão cansativo quanto démodé, é, antes de tudo, uma construção social. Por isso mesmo, não poucos dos pesquisadores que se aventuram a abordar sociologicamente a corrupção, o fazem nessa perspectiva construtivista. Esse é o caso de Mark Granovetter, um dos mais importantes cientistas sociais norteamericanos das duas últimas décadas, que aborda as práticas de corrupção a partir das ferramentas heurísticas fornecidas pelo "movimento teórico" identificado como Nova Sociologia Econômica. Assim, Granovetter (2005) propõe-se a analisar as práticas de corrupção como expressões de transações econômicas singulares. Essa aposta analítica se traduz na proposição de que as práticas de corrupção seriam apreensíveis a partir de uma análise das gramáticas sociais e culturais dos universos nos quais estão inseridas.

Nos últimos anos, e não apenas no Brasil, a corrupção tem sido uma das principais bases para a emergência do que poderíamos denominar, seguindo de perto as indicações de Thompson (2005), de midiatização da atividade política. Essa midiatização, fenômeno expressivo das transformações da esfera pública dos últimos decênios, traduz uma "nova visibilidade" das elites dirigentes. Com o desenvolvimento das novas tecnologias de informação, em especial aquelas que permitem uma "intimidade não-recíproca", como a TV, temos um aprofundamento de uma tendência não exatamente nova: a teatralização da vida política. 0 "escândalo político" é a melhor expressão dessa teatralização.

Nãoéexagero afirmarqueosintagma "escândalopolítico" passou amodular cada vez mais a disputa política nas sociedades ocidentais. E essa modulação é tanto maior quanto mais autônomos em relação ao executivo forem o parlamento e o judiciário. E, é óbvio, quando esses elementos institucionais coexistem com um mercado de bens culturais relativamente consolidado, traduzido, dentre outros elementos, em uma imprensa organizada empresarialmente.

As observações acima ilustram a importância e a legitimidade intelectual de uma análise sociológica dos escândalos de corrupção. Até porque são poucas as 
incursões sociológicas sobre as gramáticas sociais e os mundos morais aos quais os escândalos de corrupção remetem no Brasil.

Antes de prosseguir, é sensato que eu esboce uma pequena justificativa da afirmação acima. Não se trata exatamente do fato de que inexista uma produção sociológica significativa sobre a gramática social subjacente às práticas de corrupção no Brasil. Muito pelo contrário! Nenhum problema de investigação impulsionou mais a produção do campo das ciências sociais brasileiras do que aquele dedicado à investigação sobre as bases sócio-culturais e econômicas da corrupção. De certa forma, essa produção, reflexivamente incorporada pela própria sociedade brasileira, é tão forte que, hoje, constitui-se em parte do arsenal discursivo mobilizado pelos atores políticos para a construção de justificativas em suas disputas ordinárias. Entretanto, aí é que está o problema, essa produção geralmente toma as "fontes morais" subjacentes às práticas de corrupção como traduções de uma cultura nacional (ou "cultura política brasileira") mais ou menos uniforme. Por isso mesmo, há uma trilha a ser explorada nessa densa floresta dos eventos comumente identificados na rubrica de "escândalos de corrupção": que fontes morais são essas às quais os atores recorrem para enfrentar (como denunciantes ou acusados) os casos concretos que atraem a atenção das pessoas no Brasil?

Explorar a questão acima pode ser uma forma de ampliar a compreensão do que está em jogo em cada um dos escândalos. E essa é uma tarefa analítica que deve ir além da identificação dos móveis das disputas de posições no campo político em um momento histórico particular. Assim, ao se especular sobre o que "está em jogo" em cada escândalo de corrupção, a análise sociológica estará interessada em apreender os mundos morais e os modelos de justiça que são colocados à prova em cada evento concreto.

Como abordar sociologicamente os escândalos de corrupção produzidos nos últimos anos no Brasil? No que segue, embora não descarte (e até incorpore) algumas das clássicas elaborações sobre a permeabilidade do Estado aos interesses privados no Brasil, preocupamo-nos em abordar centralmente as lógicas sociais e as gramáticas morais expressas e mobilizadas pelos atores revelados pelos escândalos de corrupção. Para tanto, tomarei como referência a produção legislativa relacionada à CPMI dos Correios, base propulsora da crise política que abalou 0 final do primeiro mandato do Presidente Lula e o Partido dos Trabalhadores, em 2005, a chamada "crise do mensalão". 


\section{Os DESAFIOS DE UMA SOCIOLOGIA DOS ESCÂNDALOS}

Em artigo que, não por acaso, procurou abordar o "Escândalo do Mensalão", Grun (2008) apresenta uma competente explanação das principais abordagens sociológicas do escândalo. Não vou reproduzi-las, pois, no máximo, repetiria de forma caricatural algo que está explicitado, com síntese e elegância, no texto anteriormente referenciado. Importa ressaltar, entretanto, para os objetivos colocados para este artigo, que a aposta analítica de Grun, embora chegue a fazer referência a Luc Boltansky e Eve Chiapello segue, no geral, uma linha bourdeusiana tradicional. Essa aposta analítica o conduz a apreender os eventos ligados ao "mensalão" como expressivos de uma "guerra cultural" de posições no campo de poder no Brasil, mas deixa alguns flancos em aberto e é exatamente deles que se tratará aqui. É bom que se esclareça que o objeto de análise de Grun não é o "mensalão", exclusivamente, mas o "ambiente econômico" da singular "financeirização tropical", na qual os fundos de pensão passaram ocupar, não sem resistências diversas, razoável saliência no cenário econômico do país. Esse fato, acentuado com a ascensão do Governo Lula, teria dado novos contornos às disputas no "campo do poder". Nessas disputas, idéias-forças a respeito do mercado, do lugar do Estado na economia e, em particular, do significado do processo de privatização levada a cabo na segunda metade da década de 1990, pelo Governo do Presidente Fernando Henrique Cardoso, funcionariam como mapas culturais. E esses mapas são arsenais mobilizados, especialmente quando a "guerra" anteriormente referida transmuda-se em disputas políticas, como no caso das investigações conduzidas nas CPMIs dos Correios e da "Compra de Votos", e em disputas eleitorais gerais.

0 resultado alcançado pela investida analítica de Grun explicita os limites de uma abordagem ancorada nos aportes teóricos fornecido pela "teoria dos campos", tal como formulada em diversas de suas obras por Pierre Bourdieu. Não que realidades significativas deixem de ser desveladas, ao "fim e ao cabo". E, menos ainda, que deixemos de tomar pé a respeito do impacto social e político da guerra de posições em um campo no qual se disputa o capital que, em última instância, é o "conversor universal" de todos os capitais (Bourdieu, 2006). Entretanto, há algo que, dado o próprio escopo analítico escolhido por Grun (a "guerra" que teria começado com o "Escândalo do Mensalão" e teria sido concluído com o final do segundo turno da eleição presidencial de 2006), termina sendo sub-analisado: as "fontes morais" que estiveram à prova, por exemplo, nos embates ocorridos na CPMI dos Correios. 
Na verdade, não são poucas as armadilhas colocadas para uma análise mais rigorosa dos escândalos políticos. A primeira delas é a tentação, na qual sucumbem mesmo autores que fazem juras de amor ao construtivismo sociológico, de se deixar enredar pelas "facilidades" explicativas fornecidas pelas abordagens essencialistas. Esse o caso em que, contrabandeando, quase sempre inconscientemente, "categorias nativas", termina-se por evidenciar o quanto há de "fabricado" no escândalo que se busca analisar. 0 pressuposto lógico dessa abordagem é a cavilosa noção, muito confortável para alguns dos atores envolvidos, de que existiriam escândalos mais verdadeiros do que outros.

Uma segunda arapuca apresenta-se dissimulada nos estudos a respeito do papel da mídia na produção dos escândalos. 0 problema, nesses trabalhos, não é a acentuação um tanto quanto exagerada do papel dos mídias na produção dos escândalos, mas, sim, a não-percepção de algo trivial: um escândalo só é possível de ser "fabricado" quando conecta-se a mapas culturais e mundos morais profundamente enraizados. Dessa forma, podemos concordar com a assertiva mais abaixo, proposta por Thompson (2005), sem que isso implique em descurar das tarefas analíticas que nos levam a uma mais sofisticada ciência social da moral.

Esse fenômeno moderno do escândalo midiatizado tem uma estrutura dinâmica distinta, que implica a revelação pelos mídias de certas ações ou atividades que situam-se fora do escrutínio do público. Essa revelação expressa transgressão de valores e normas que, tornados visíveis, suscitam expressões públicas de desaprovação e indignação (THOMPSON, 2005, p. 77).

Há também uma elaboração, por certo mais forte no meio jornalístico do que no campo das ciências sociais, que, expressando uma imodéstia desmesurada, sobreleva de tal forma o papel dos mídias que estes passariam a ser como que a própria expressão da disputa política. Esse tipo de elaboração encontra algum apoio também na obra de Thompson. Para este estudioso da comunicação, o escândalo político funcionaria como que uma espécie de produção política possível em um mundo no qual "o declínio progressivo da política ideológica significa igualmente que, no sub-campo dos políticos profissionais, os objetos de desacordo fundamentais sobre questões de princípios são menos pronunciados" (THOMPSON, 2005, p. 83). A sedução funcionalista do argumento não é desprezível: na medida em que a política se despolitiza, os partidos políticos buscam preencher 0 vazio evidenciando as falhas morais e as aventuras sexuais das figuras proeminentes adversárias. 0 problema da argumentação, obviamente, 
não está no fato de ser funcionalista, mas em deixar passar sem registro uma quantidade razoável de aspectos do fenômeno para o qual pretende se apontar as baterias investigativas. Essa apreensão crítica não implica em uma avaliação negativa a respeito da contribuição das elaborações de Thompson para a apreensão sociológica do fenômeno do "escândalo político". Longe disso! Como se verá mais adiante, incorporo alguns aportes fornecidos pelas elaborações desse autor para dar sentido a alguns aspectos explicitados pelos escândalos de corrupção.

\section{CORRUPÇÃO: PRINCÍPIO DE NEUTRALIZAÇÃO, HABILIDADES E SENTIDOS}

Mark Granovetter aborda criticamente algumas daquelas elaborações mais tradicionais a respeito da corrupção, muito referidas no jornalismo diário e em certa ciência política, que se vendem como análises políticas, mas que, em verdade, não deixam de expressar proposições semi-doutas, assentadas no senso comum. Esse o caso daquela visão tradicionalmente aceita pelos bem-pensantes, que apreende a corrupção como uma "traição". No caso, traição a uma responsabilidade ou função pública.

Granovetter (2005), tomando como referência uma das definições de corrupção esposada pelo dicionário 0xford, que a toma como "perversão ou destruição da integridade no cumprimento de deveres públicos, através de suborno ou favor", propõe-se a problematizar o que sejam as práticas de corrupção. Para tanto, aborda-as como transações econômicas específicas. E, enquanto tais, passíveis de serem compreendidas a partir dos quadros interpretativos da sociologia econômica. Essa aposta analítica o leva a considerar o "encaixamento" das ações econômicas no seu universo social. No que nos interessa mais de perto, isto é, as práticas de corrupção, também estas seriam apreensíveis a partir de uma análise das gramáticas sociais e culturais dos universos nos quais estão inseridas.

Um primeiro ganho possibilitado pela abordagem de Granovetter é uma relativização da definição de "integridade" na função pública, um dos pilares sobre o qual se constrói comumente a definição de corrupção. Exemplar desse tipo de apreensão é o arsenal retórico mobilizado por organizações como a Transparência Brasil, ou por setores do Ministério Público brasileiro. Nas abordagens produzidas por esses atores pululam avaliações moralistas e a históricas. Caminho diametralmente oposto segue Granovetter (2005, p. 11): "0 que vem a ser 'integridade' no cumprimento de deveres públicos ou outros é algo 
que se define por normas sociais e profissionais que variam no tempo e no espaço. E o significado de "suborno" é negociável e elástico".

Um segundo importante aporte fornecido pela abordagem proposta por Granovetter é a incorporação, na análise sociológica das práticas de corrupção, da noção de habilidade social. Esta noção, no quadro teórico formulado pelo autor, torna-se uma chave de leitura para interpretarmos as condições necessárias para 0 êxito das transações comumente designadas como corruptas. Apoiado no trabalho etnográfico desenvolvido pelo antropólogo Akhil Gupta, a respeito do fracasso de camponeses pobres indianos em subornarem funcionários públicos (GUPTA, 2005), Granovetter aponta que uma habilidade social fundamental, no caso da corrupção, é a de neutralizar os sinais de "deficiência moral" das ações empreendidas pelos atores envolvidos em tais práticas.

A habilidade também está relacionada à capacidade de lidar com interlocutores situados em posições sociais distintas. No caso de suborno, por exemplo, isso implica em saber o que podem fazer e como devem se comportar os agentes ativos ou passivos de uma transação dessa natureza. Muito embora, as análises de escândalos de corrupção indiquem que a linha demarcatória entre inabilidade do ator e contexto de risco seja muito tênue.

A habilidade, no que diz respeito às elites políticas, diz respeito, em especial, ao monitoramento reflexivo das suas ações mais ordinárias. Isso porque, em um mundo no qual a audiência da elite deixou de ser a própria elite, nas suas relações de co-presença, e passou a ser o público em geral, a visibilidade midiatizada dos atos da elite passa a exigir um autocontrole antes desnecessário. Não é por acaso, portanto, que sejam imagens e gravações produzidas através do uso de modernas tecnologias de comunicação (na maioria das vezes realizadas ilegalmente) os estopins de "escândalos políticos".

Antes de prosseguir, vale a pena nos determos um pouco na proposição de que as transações tidas como corruptas são realizadas, em parte, pela mobilização, pelos atores envolvidos, do "princípio de neutralização". Este princípio é definido da seguinte forma:

[... os indivíduos cientes das ações em questão aceitam o que chamo de um "princípio de neutralização": um registro que reconhece a relação causal entre um pagamento e um serviço, ou que favores foram recebidos em função de uma posição ocupada, mas sugere que dadas as circunstâncias específicas do caso, não houve nenhuma violação moral (GRANOVETTER, 2005, p. 12). 
Implícita a essa proposição, encontra-se uma apreensão muito disseminada na sociologia: a de que as ações desenvolvidas pelos atores expressariam, de algum modo, uma gramática generativa consolidada pela in-corporação de um babitus ao longo de toda uma trajetória existencial. Tudo se passaria, então, como se, nos casos de corrupção, por algum momento, os princípios fossem "suspensos".

0 problema dessa elaboração teórica é menos a forma limitada como enfrenta o tradicional "problema" sociológico da relação indivíduo-sociedade, mas, centralmente a sua limitação em fornecer aportes para a análise de situações nas quais os arsenais mobilizados para a apreensão da socialização mais do que deslocados, parecem inapropriados para apreender jogos relacionais, contingentes e precariamente ancorados no que diz respeito aos seus suportes institucionais. Necessitamos, pois, na análise dos escândalos de corrupção e das transações econômicas por eles reveladas, de apoios teóricos menos focados nas dimensões estruturais. Somente assim poderemos iluminar algumas áreas um tanto quanto obscurecidas das disputas políticas atuais.

Nos tópicos seguintes, aponto alguns elementos que podem ser tomados como uma espécie de mapa orientador de uma análise sociológica dos escândalos de corrupção. A ambição, impossível de ser alcançada nos limites do presente texto, é a de constituir pontes para a instituição entre nós de uma sociologia da moral. A referência empírica das proposições é fornecida pelo "Escândalo do Mensalão", evento que marcou o final do primeiro mandato do Governo Lula, entre 2005 e 2006.

\section{O “MENSALÃO": UMA PROVA E SEUS VALORES}

Em meados de 2005, ao observador mais arguto da vida política brasileira não faltaria referentes para justificar a atualidade de passagem famosa da mais célebre obra de análise política produzida por Karl Marx. Tudo se passava, então, como se os personagens da CPI do Orçamento, criada pela Câmara dos Deputados em 1993 para investigar as ações dos chamados "anões do Orçamento", tivessem tido uma segunda chance de reencenar seu tragicômico "escândalo". A publicação de matéria na revista Veja, abordando casos de subornos que seriam pagos por dirigentes de empresas prestadoras de serviços aos Correios, e que esses subornos seriam carreadas para uma "caixinha" partidária de uma das agremiações partidárias integrantes da base de apoio ao Governo Lula, parecia ter aberto uma caixa de Pandora da qual saiam fatos que transformavam os antigos mocinhos de 1993 em vilões. E, como complemento, quem antes ocupara a incômoda posição de companheiro de viagem do partido dos vilões, os "anões", passava a saborear a 
condição de mocinho. Para completar, algumas das situações protagonizadas pelos dirigentes do Partido dos Trabalhadores (PT), em especial José Genoíno, Delúbio Soares e Sílvio Pereira, afirmando algo hoje para desmentir amanhã, lembravam histórico depoimento dado pelo Deputado João Alves (PFL-BA), durante anos o todo poderoso da Comissão de Orçamento da Câmara dos Deputados. Em uma das reuniões da CPI, transmitida ao vivo por algumas emissoras de televisão, o deputado baiano saiu-se com a seguinte justificativa para os sinais explícitos de enriquecimento que apresentava: "Deus me ajudou e eu acertei duzentas vezes na loteria". 0 fato era verdadeiro, em parte, como o provaram as investigações conduzidas pelos parlamentares da CPI do Orçamento. A loteria era usada para "lavar" o dinheiro abiscoitado de entidades beneficentes de fachada para quem os "anões" alocavam recursos em emendas orçamentárias acrescentadas sem 0 consentimento e controle do plenário da Câmara.

Obviamente, nem mesmo o mais fundamentalista dos anti-petistas equalizará as ações dos dirigentes petistas, condenadas ao limbo após a eclosão do "Escândalo do Mensalão", com os descalabros do Deputado João Alves e o seu cortejo de "anões", revelados no início da década de 1990. Entretanto, há um cenário de fundo presente nos dois casos. Refiro-me à "visibilidade midiática" (THOMPSON, 2005) como elemento modulador da atuação (e da avaliação das ações dos atores) na esfera pública. 0 peso das transmissões televisivas, tanto no "Escândalo do Orçamento" quanto no "Mensalão", expressam essa midiatização da vida política.

Sobre a articulação entre escândalos, midiatização e atividade política já existe um bom acúmulo de literatura, em especial no campo dos estudos de comunicação. 0 que importa reter aqui é algo que geralmente escapa, ou é tratado secundariamente nessa produção: a legitimidade dos atores políticos passou a ser, nas situações políticas modeladas por aquela "visibilidade", como de resto todo o processo de busca de legitimação das instituições modernas, cada vez mais subordinada à contínua conquista da "confiança ativa" (GIDDENS, 1993). E quando a "confiança ativa", isto é, buscada reflexivamente por atores e instituições, passa a modelar as relações no espaço público, os contextos e formas de expressão das disputas políticas tendem a ser radicalmente alterados.

Os atores políticos, e não apenas no Brasil, têm tido enormes dificuldades em lidar com essa nova situação. Parece escapar-lhes a compreensão de que, nas sociedades atuais, as pessoas dispõem de informações que lhes possibilitam a elaboração de avaliações rigorosas (ou, de forma mais concreta, um 
"monitoramento") de seus interlocutores, presenciais ou não. Assim, a confiança nunca está dada, como ocorria nas instituições das sociedades tradicionais. Hoje, esse precioso bem que é a confiança necessita ser cotidianamente (re)conquistado.

Qual a conseqüência dessa mudança estrutural para a análise de um "escândalo político"? A lógica subjacente a esse novo tipo de confiança ("ativa") dinamita a fixidez do valor de bens e produtos nos mercados políticos e culturais. Em consequiência, esse capital torna-se muito mais volátil do que antes, dado que acúmulos pretéritos não garantem um bom desempenho no presente. Assim, nem o domínio das engrenagens de alocação de verbas orçamentárias e nem 0 conhecimento detalhado a respeito do envolvimento de colegas parlamentares na manipulação para fins privados de verbas públicas serviram de garantias para 0 Deputado João Alves. Pouco mais de uma década depois, o mesmo viria a ocorrer com o então Presidente do PT, José Genoíno, não no seu depoimento diante de um plenário lotado por ex-colegas parlamentares quando de sua inquirição no Congresso no "Escândalo do Mensalão", mas nas suas performances nos meios de comunicação. Os desmentidos e as demonstrações de alheamento em relação ao cotidiano da máquina partidária do PT (a gestão dos "empréstimos" intermediados pelo publicitário Marcos Valério) dinamitaram um capital acumulado durante décadas. Ex-guerrilheiro, parlamentar competente e alguém que, segundo todos os testemunhos, jamais teria se envolvido em negócios escusos para fins privados, Genoíno foi condenado ao inferno do ostracismo, e, mesmo tendo sido eleito deputado federal, em 2006, não conseguiu reconstituir o seu capital anterior.

Muito já se escreveu na imprensa brasileira nas duas últimas décadas sobre o caráter "revelador" dos "escândalos políticos". Em verdade, essa "leitura" do mundo também se introduz no universo acadêmico, não sendo poucos os textos encontráveis em periódicos ou em anais de evento que tomam essa perspectiva "religiosa" como trilha analítica a ser explorada. Assim, escândalos, como o do "Mensalão", seriam reveladores, por exemplo, dos elementos estruturais de uma "cultura política" pouco moderna. Em texto inspirado, mas limitado pela amarra ao universo bourdieusiano que o impede de apreender o contingente e o nãoestrutural, Sousa (2009) dinamita essa cavilosa "sociologia do jeitinho brasileiro". Procurando apreender a força persuasiva desse tipo de leitura, denominada por ele de "conservadora", Sousa explicita a inserção dessa abordagem no seio da produção ideológica legitimadora da desigualdade social brasileira:

[...] a eficácia de suas idéias se explica por confundir fenômenos muito diferentes entre si: nomeadamente na confusão entre a inegável influência do 
'capital social nas relações pessoais' para as chances de sucesso pessoal de qualquer indivíduo em qualquer sociedade moderna, com o fato, muitíssimo diferente, de que uma dinâmica e complexa (ainda que injusta e desigual) sociedade como a brasileira seja 'estruturada', pelo 'capital de relações pessoais'. Como a acesso aos capitais 'impessoais' econômico e cultural - que se transmitem por heranças afetivas e intelectuais no interior das famílias das classes privilegiadas - éo segredo mais bem guardado num tipo de dominação social que só vê os indivíduos e esconde as classes que os formam, a cegueira da teoria duplica a cegueira da dominação social incrustada no senso comum que todos compartilhamos. É isso que garante a 'compreensibilidade' imediata de teorias conservadoras e superficiais que se baseiam no 'capital social de relações pessoais (SOUSA, 2009, p. 77, grifo do autor).

Fiz questão de inserir o trecho acima porque o mesmo é emblemático. Expressa tanto um avanço quanto um impasse na produção de uma sociologia do que, no mesmo texto, Sousa identifica como nossa "dimensão 'moral", isto é, "a dimensão na qual separamos o 'bem' do 'mal', o 'nobre' do 'vulgar', o 'superior' do 'inferior'...”. (SOUSA, 2009, p. 109). 0 avanço é expresso pela superação da armadilha "culturalista", abordagem ancorada na pressuposição de uma "cultura" uniforme, base da vida social. Esse restolho do essencialismo ainda encontra ecos entre nós. Tanto assim que, não raro, crime e violência são "lidos", especialmente na produção sociológica que chega, como "folclore", ao senso comum, através de expressões utilizadas cotidianamente como "cultura brasileira". Em que pese o acento desmesurado à interpretação baseada no modelo explicativo bourdieusiano das classes sociais, Sousa acerta o alvo, nesse quesito específico, e nos ajuda a afastar a densa nuvem de fumaça ideológica que emerge da produção discursiva sobre o "Escândalo do Mensalão". Entretanto, exatamente porque toma os insights fornecidos pela instigante teoria sociológica de Bourdieu como ponto de partida, Sousa está impossibilitado de atentar, não para a gramática moral profunda, suporte "necessário" (a provocação é minha!) da naturalização da desigualdade social brasileira, mas para as gramáticas morais ordinárias que, mobilizadas cotidianamente, mesmo que de forma precária e marcadamente contingente, asseguram a produção de avaliações morais nas interações pessoais e institucionais dos brasileiros.

É essa dimensão que, no meu entender, escapa não apenas ao projeto teórico de Jessé Sousa, mas também a todos quantos procuram apreender os "escândalos políticos" a partir da perspectiva analítica da estratégia. Em realidade, essa também tem sido uma forma de apreensão do mundo expressa pelos atores 
envolvidos na voragem dos escândalos. Esse o caso dos intelectuais e dirigentes do Partido dos Trabalhadores, após a ascensão de Lula à presidência da República. Nas suas elaborações, tudo se passa como se as denúncias expressassem, no melhor dos casos, meras disputas de poder. Foi esse, aliás, o mote do discurso justificativo apresentado nos depoimentos à CPMI dos Correios por Delúbio Soares e Sílvio Pereira, respectivamente o tesoureiro e o secretário do partido nos primeiros anos da chegada do PT ao Palácio do Planalto. Ora, se os escândalos têm vida social é porque, como nos lembram De Blic e Lemieu (2005), há algo que lhes dá suporte, para além dos lances imediatos do jogo: valores partilhados anteriores ao evento tido como escandaloso pelos membros de um grupo social.

$\mathrm{Na}$ leitura que proponho, para além dos elementos constitutivos da "gramática moral profunda", base das "fontes morais" (SOUSA, 2009) hegemônicas em uma dada sociedade, passíveis de serem apreendidos pela grade analítica de classes, temos valores generalizados, que não podem ao menos imediatamente ser abordados a partir da perspectiva classista. Se resgatarmos um pouco a produção discursiva a respeito dos dois escândalos políticos brasileiros anteriormente mencionados, constataremos que foram valores, transversais às classes sociais, que se apresentaram como moduladores da leitura dos acontecimentos feitos ordinariamente pelos brasileiros. Poderia sintetizá-los em duas palavras: "verdade" e "transparência". Adianto que esses valores são também "categorias nativas", isto é, formas de apreensão e classificação do mundo que são mobilizadas fartamente pelos atores políticos brasileiros nas duas últimas décadas.

Por "verdade", refiro-me, no caso de personalidades públicas, submetidas ao escrutínio da visibilidade midiatizada, à coerência do personagem apresentado ao público. Essa coerência não se traduz necessariamente em credibilidade, mas necessita ter uma estrutura (quase diria, um "script") plausível. Assim, essa "verdade" não é a negação de toda mentira, mas a não-utilização de recursos discursivos diante dos quais as pessoas percebam que estão sendo deliberadamente trapaceadas. E foi exatamente isso o que fez derreter como neve no sol o capital político dos dirigentes petistas em 2005.

"Transparência" pareceria coincidir com "verdade", mas remete a outros significados, tais como a realização de atos que possam ser facilmente explicados e assimilados pelas pessoas. Como se pode observar, não estou assumindo aqui que, a priori, "verdade" e "transparência" sejam valores, em si mesmo, positivos. São marcadores relacionais, mobilizados em situações concretas, e, portanto, podem alimentar também processos sociais danosos, especialmente porque 
tendem a impulsionar, em algumas situações, a desconfiança em relação a atores e processos envolvidos com atividades complexas, que não podem ser aferidas por oposições simplistas. Penso, em particular, nas ações dos membros do judiciário. Mas a apreensão também poderia ser estendida a outros campos sociais, como o científico, para citar apenas mais um exemplo. Poder-se-ia ainda traduzir "transparência" pela cobrança de que os "jogadores" não sejam "mascarados". Trata-se de rejeitar o jogador/ator com "duas caras". Valor ambíguo, "transparência" expressa também conformismo e preconceito contra os que buscam redefinir o seu lugar no mundo. Por isso mesmo, mobiliza a força social oriunda dos discursos entronizados pelos manuais de auto-ajuda, o que se traduz na consigna: "seja você mesmo!".

Por outro lado, mesmo os atores dotados de autocontrole extremo (algo impossível para qualquer jogador em qualquer campo social), que pareceriam, à primeira vista, habilitados para vencer qualquer prova modulada pelos valores acima identificados, nem sempre tenham garantidas as suas vitórias nos embates ordinários. Como a prova, isto é, o acontecimento no qual os atores em confronto medem-se e medem os seus valores, contém sempre uma grande margem de imprevisibilidade, há sempre a possibilidade de que a "coerência" pretérita seja alguma garantia para enfrentar os testes do presente. Algumas vezes, sói ocorrer todo o contrário: a coerência de ontem, especialmente se mobilizada pelo ator para se legitimar perante o público, pode torná-lo muito mais vulnerável para justificar os deslizes de hoje. Foi o que ocorreu com o PT durante o "Mensalão".

Se os escândalos podem ser entendidos também como provas (BOLTANSKY; CHIAPELLO, 2009), o que a análise dos escândalos nos indica é o fato de que "verdade" e "transparência" são, na realidade política brasileira, os seus moduladores. Entretanto, e é exatamente aí que reside a riqueza da análise sociológica baseada na noção de prova, não está estabelecido como os valores moduladores ressoarão em cada caso concreto. Esse o pulo do gato da análise pragmática das práticas sociais! Assim, não é pelo fato de aqueles valores modularem as provas (os "escândalos") que eles terão sempre o mesmo peso. Na maioria das vezes, o jogo está em aberto e os jogadores procurarão mobilizar conquistas obtidas em outras provas para minimizar os prejuízos naquela que ocorre no presente, na qual se encontram em franca desvantagem.

\footnotetext{
2 "Jogador mascarado" é um sintagma usado mais fortemente para categorizar os jogadores de futebol, traduz também uma gramática mais geral de apreensão das performances das pessoas nas mais diversas esferas da vida social.
} 
Essa situação se traduz na incerteza que marca cada prova. E os atores têm uma consciência aguda disso tanto que, no que diz respeito ao dia a dia do Congresso Nacional, nenhum lugar-comum é mais repetido do que "a gente sabe como uma CPI começa, mas não sabe como ela acaba". Obviedade em relação a toda e qualquer situação que implique conflito e coordenação entre atores distintos, a frase não é tão banal (ou idiota) quanto parece. Ao proferi-la, os políticos brasileiros têm em mente não apenas os esqueletos que sairão dos armários, mas também os imprevisíveis resultados da leitura feita pelo público a respeito de suas performances. Importa ressaltar que, na prova, como nos jogos comuns da vida social, não se escolhe participar ou não. É-se levado. Assim, em determinadas circunstâncias, os atores não podem simplesmente se negar a participar de uma prova.

Essa incerteza da prova é realçada, em uma ilustrativa nota de rodapé da obra Boltansky e Chiapello (2009), mais acima mencionada. Vale a pena, mesmo sendo extenso o trecho a ser transcrito, citá-la aqui:

Essa incerteza refere-se ao estado dos seres, objetos ou pessoas e, em particular, a seu poder respectivo, do qual depende o lugar que ocupam nos dispositivos que enquadram a ação. Num mundo onde todos os poderes fossem fixados de uma vez por todas, os objetos fossem imutáveis (por exemplo, não estivessem sujeitos ao desgaste) e as pessoas agissem segundo um programa estável e conhecido por todos, a prova sempre seria evitada, pois a certeza de seu resultado a tornaria inútil. Visto que as possibilidades dos objetos (como quando se fala em testar as possibilidades de um veículo) e as capacidades das pessoas por natureza (nunca se sabe com certeza aquilo de que as pessoas são capazes), os seres entram em relações de enfrentamento e confronto, e é aí que seu poder seu revela (BOLTANSKY; CHIAPELLO, 2009, p. 566).

Voltando ao nosso objeto, o "Mensalão", não seria demasiado especulativo afirmar que, nele, o que esteve colocado em prova foi menos a honestidade e mais a "verdade" e a "transparência" do PT e do Governo Lula. Essa prova, para a qual o PT foi "impelido" a participar, muito a contragosto", não teve os resultados a médio e longo prazo esperados pelos atores principais ${ }^{4}$.

\footnotetext{
${ }^{3}$ Há que lembrar o ambiente político que antecedeu à instalação da CPMI dos Correios, marcado por ameaças da direção partidária aos parlamentares do PT e da "base aliada", para impedir que os mesmos assinassem o requerimento de instalação da CPMI.

${ }^{4}$ A expectativa de alguns atores de que o "Mensalão" fizesse o Governo Lula "sangrar" publicamente até a eleição de 2006, favorecendo a vitória de uma candidatura oposicionista, mostrou-se uma quimera.
} 


\section{O “MENSALÃ̃” E A GUERRA DOS MUNDOS}

Uma situaçã̃o que, enfrentada convenientemente, faria emergir novos cenários políticos e morais, essa uma apreensão possível de um "escândalo político". Daí ser quase uma tentação, na análise sociológica de um escândalo específico, enquadrar os atores envolvidos em posições precisas (especialmente quando o "escândalo" acentua a polarização política), e se buscar identificar os "empreendedores morais" do caso. A referência básica para esse tipo de empreendimento investigativo é a já clássica obra de Becker (2008). Na verdade, 0 capítulo intitulado "Empreendedores morais" pode fornecer importantes insights para se pensar a dinâmica de um "escândalo". Entretanto, as elaborações desse autor, tal como aquelas de Bourdieu, podem funcionar bem quando tomadas como horizontes moduladores, mas impõem limitações quando são tomadas como pontos de apoio e de partida para a análise. Isso porque, no que diz respeito a Becker, a noção de "empreendedores morais" fornece elementos suficientes para reduzir a análise sociológica do "escândalo político" à sua dimensão de jogo estratégico ${ }^{5}$.

Em relação ao "Escândalo do Mensalão", não apenas supostos analistas, mas também alguns dos seus principais atores alimentaram esse tipo de abordagem. Aos últimos, trata-se de um recurso justificativo conveniente: tudo não passaria de uma "disputa pelo poder". Essa sofisticação perde força, e transmuda-se em teorias conspirativas diversas, quanto mais nos aproximamos das elaborações discursivas produzidas pelos intelectuais e redes de comunicação (blogs, por exemplo) mais próximos à base partidária petista. Por isso mesmo, torna-se importante apreender os mundos que estiveram em confronto na CPMI dos Correios, um dos esteios da "crise do Mensalão", distanciando-nos dessas perspectivas "convenientes".

Os depoimentos dados pelos acusados de envolvimento com práticas de corrupção na Empresa Brasileiras de Correios (ECT) ou na relação com a estatal, base estrutural do "Escândalo do Mensalão", fornece indicadores para uma análise dos mundos em confrontos. Não raro, percebemos o etnocentrismo de classe média de alguns dos parlamentares inquiridores, especialmente daqueles que representavam a defesa da ética com "E" maiúsculo, para retomar aqui linha

\footnotetext{
${ }^{5}$ Esse o caso, por exemplo, da seguinte passagem, que conclui o capítulo mencionado: "cumpre ver o desvio, e os outsiders que personificam a concepção abstrata, como uma consequiência de um processo de interação entre pessoas, algumas das quais, a serviço dos seus próprios interesses, fazem e impõem regras que apanham as outras - que, a serviço dos seus próprios interesses, cometeram atos rotulados de desviantes" (BECKER, 2009, p. 168).
} 
de análise proposta por Oliveira (2008). Era o caso das cobranças para que os investigados elaborassem avaliações subjetivas de situações ou casos de tráfico de influência ou suborno dos quais foram protagonistas.

Obviamente, em alguns momentos, a incapacidade de estabelecimento de comunicação entre os parlamentares e os depoentes poderia derivar de uma estratégia de defesa dos segundos. É o que ocorre ordinariamente em boa parte dos interrogatórios, especialmente naqueles nos quais os inquiridores cobram avaliações dos suspeitos. Entretanto, quando analisamos de forma mais acurada passagens como aquela contida no trecho destacado no quadro abaixo, damonos conta de que mundos distintos estão se encontrando. De um lado, um distanciamento objetivo que permite ao inquiridor, no caso um parlamentar com formação e atuação no campo do direito, uma construção intelectualista da moral; do outro, alguém cujos mapas mentais permitem uma navegação naturalizada nos ambientes da permeabilidade do Estado aos interesses privados. 0 depoente, Maurício Marinho, pivô do escândalo do Mensalão, parecia incapaz, mesmo quando disposto a ser colaborativo com os parlamentares da CPMI, de ir além das coisas ordinárias de seu mundo. Ele fazia o que se esperava que alguém, na posição dele, fizesse. E o mais tragicômico, para Marinho, foi que quando buscou alçar vôo próprio, tentando "levar algum" para si próprio, caiu na armadilha que o levou à indesejada fama de recebedor de propina, sendo capturado em célebre gravação clandestina. No fundo, Maurício Marinho era um personagem que fazia exatamente o que se esperava dele. Funcionário de carreira de uma empresa com grandes negócios com a iniciativa privada, ele somente conseguiu superar uma demissão e ser readmitido na empresa devido às suas ligações com lideranças partidárias tradicionalmente governistas. E foi através delas que conseguiu ser alçado a um cargo de direção que, muito provavelmente, situava-se bem acima de suas expectativas profissionais.

"0 Sr. JOSÉ EDUARDO CARDOZO (PT-SP) - Considerando que o seu chefe foi indicado por ele considerando que o seu subordinado foi indicado por ele e considerando que o senhor também foi indicado por um deputado do partido de Roberto Jefferson, a minha pergunta é a seguinte: isso não é tráfico de influência? Não épressão? Não é uma forma de fazer com que V. $S^{a}$ dê um tratamento preferencial para este caso? Se o senhor atende todo mundo, por que o genro de Roberto Jefferson tinha de pedir para o senhor atender, em caráter especial, uma empresa? 
O Sr. MAURÍCIO MARINHO - Não, ele estava visitando a empresa e foi com fornecedor até a minha sala, e eu o atendi.

O Sr. JOSÉ EDUARDO CARDOZO (PT-SP) - Não, o senhor falou que ligou. No caso da Canon, bouve uma ligação, e o senhor falou isso.

O Sr. MAURÍCIO MARINHO - Houve uma ligação.

0 Sr. JOSÉ EDUARDO CARDOZO (PT-SP) - Por que ele ligaria para o senhor para atender uma empresa, se o senhor atende a todos? E o senhor não acha estranho o genro da pessoa, o Presidente do Partido que o indicou, pedir-lhe um favor para uma empresa? E o senhor não tomou cuidados? Por que o senhor não falou "venha o empresário aqui, que eu atendo todo mundo, Sr. Marcus"?

O Sr. MAURÍCIO MARINHO - Mas ele foi e foi atendido, e foi dada a resposta.

O Sr JOSÉ EDUARDO CARDOZO (PT-SP) - E por que o Marcus precisa ligar para o senhor?

O Sr. MAURÍCIO MARINHO - Mas ele quis ligar e ligou. Ele ligou para eu atender, eu atendi.

Fonte: Relatório final dos trabalhos da CPMI "dos Correios".

De um lado, um mundo no qual as práticas lidas e tidas alhures, em outros campos, como corruptas, são banais, quase triviais. Soa quase como fora de sentido a cobrança de que os indivíduos que aí navegam elaborem análises distanciadas de práticas que, ao fim e ao cabo, lhes constituem. Ora, parafraseando Bourdieu (2001), o Mauricio Marinho está nesse mundo porque o mesmo está nele.

Naturalizado, com regras que se impõem como "necessárias" ("todo mundo faz"), esse universo das transações de suborno, propina e privatização de recursos públicos não constitui exatamente o espaço das ousadias criminosas, conforme as narrativas mobilizadas por visões conspirativas alimentadas pela mídia nativa. Expressam, em verdade, um mundo moral no qual a pequenez das negociatas parece aliviar a responsabilidade individual. Os atores, em alguns dos depoimentos dados à CPMI dos Correios, percebem-se pequenos. Eles não têm expectativas grandiosas a respeito de si. Estão, assim, mais para o patético do que para o quase sedutor papel de vilão. Tanto assim que serão personagens outros, fora do cotidiano da máquina estatal, com competência para transitar no mundo dos grandes negócios, mesmo que na condição de outsiders, que representarão para a opinião pública essa grandiosidade do mal. Foi esse o caso de Paulo 
César Farias, conhecido como PC Farias, tesoureiro da campanha eleitoral de Fernando Collor de Melo em 1989. Guindado ao estrelato quando da crise que levou ao impeachment de Collor, durante muito tempo PC foi a encarnação do "vilão". Grandes somas, fotografias de notas de dólar, viagens internacionais, casas suntuosas e casos amorosos rumorosos, esses ingredientes fizeram o público amar-odiar esse personagem no Brasil do início da década de 1990, do início ao fim de sua saga, concluída de forma misteriosa com um assassinato ainda hoje não elucidado. No caso do "Mensalão", esse papel viria a ser ocupado, com menos estardalhaço, pelo publicitário Marcos Valério Fernandes de Sousa, o qual, segundo o relatório da CPMI dos Correios, seria o responsável pelo gerenciamento dos "empréstimos" bancários que alimentavam os pagamentos a parlamentares pertencentes a partidos da "base aliada" do Governo Lula, entre 2003 e 2004.

A pequenez das negociatas não significa que grandes somas financeiras não estejam em jogo. Aqui, no pantanoso terreno das negociações ilegais, os atores têm sempre uma consciência extremada de quanto valem. Alguns dos malogros ocorrem exatamente pela incapacidade que têm de saber "até onde ir". Daí que os suportes de "grandes", nesse mundo das negociatas, seja decisivo. Os "grandes", articulados ou articuladores de forças políticas, é que detêm o monopólio das negociações maiores. Obviamente, a própria justificativa dos "grandes" para o seu envolvimento nas negociações é superior àquela possível de ser produzida pelos "pequenos". Tanto assim que o Deputado Roberto Jefferson, em seu paradigmático depoimento à CPMI dos Correios, pôde jactar-se de sua "superioridade" moral em relação ao desastrado Maurício Marinho. E, falando de uma posição social distinta, enquanto "colega" e profundo conhecedor das relações que conformam o cotidiano do poder na "casa", o então deputado carioca pode justificar, em nome da "democracia", a construção de uma rede de financiamentos (privados e de recursos públicos privatizados) para os partidos políticos brasileiros.

Há seis meses, e a imprensa dá notícia disso, o Estadão $e$ o Globo já noticiaram: a Abin infiltrar agentes lá, nos Correios, para descobrir irregularidades licitatórias em contratos. A competência é tão grande que a Abin conseguiu que os seus agentes filmassem um "petequeiro", um leviano apanbando R\$3mil num movimento de contratos de bilhões, mas a Abin foi incapaz de dizer ao Governo, à Casa Civil, ao Presidente da República, ao chefe da segurança institucional do Brasil que o Sr. Marcos Valério, versão moderna (...) do Sr. PC Farias, sacava um milhão por dia nas contas do Banco 
Rural, ou sacava em Minas Gerais, ou aqui no prédio do Brasilia Shopping, no nono andar, onde muitos assessores dos que recebem "mensalão" e que estão registrados na portaria subiam até o escritório do banco para receber lá 30, 40, às vezes 20, e até $R \$ 60$ mil. O Brasil gasta uma fortuna com a Abin. Ela descobriu, através dos seus agentes, liderados pelo falso comandante que um "petequeiro" leviano usava nome de gente séria para pegar $R \$ 3$ mil, $R \$ 2$ mil. Só a TV Globo não sabe que ele é chefe de departamento. Até boje eu vejo a TV Globo colocar no ar: ex-diretor dos Correios... Porque a coisa étão pequena que, se dermos a dimensão da pequenez dela, apequenamos os nossos trabalhos: uma CPI de Srs. Senadores,

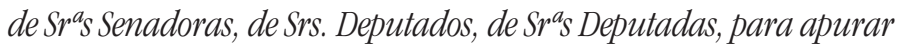
R\$3 mil que a Abin conseguiu descobrir do Sr. Maurício Marinho. Até foi bom para dar pompa e circunstância o "ex-diretor dos...". Vejo aquele moço de cabecinha assim, com um cabelinho assim meio branco, o Sr. Boner, dizendo "o ex-Diretor....". Não é, não. É chefe de departamento; équarto escalão dos Correios.

Fonte: Relatório final dos trabalhos da CPMI dos Correios.

No campo oposto, o da produção discursiva produzida pelos parlamentares guindados à condição de investigadores, sobressai um "mundo moral" no qual, no limite, como tipo ideal, as relações impessoais caracterizariam as interações entre os atores. Aqui, uma ética universalista se imporia pelo respeito às regras. Não é necessário perder muito tempo discutindo o óbvio: a inexistência em alguma sociedade presente do predomínio absoluto dessa concepção de "público". Importa ressaltar é que essa proposição (que expressa também percepções), por mais que seja contraditada pelas práticas políticas dos próprios emissores, está "aí", no contexto no qual os atores são submetidos às provas. Esse é 0 aspecto mais relevante e o que deve tomar o tempo e a atenção de uma análise sociológica das gramáticas morais subjacentes às disputas políticas.

\section{Considerações Finais}

0 que esbocei ao longo deste texto foram alguns tópicos que, desdobrados, podem constituir eixos estruturadores de uma análise sociológica dos escândalos de corrupção política. Ancorado nos aportes teóricos da Nova Sociologia Econômica, formulei a proposição de que produziremos análises mais fecundas se abordarmos as práticas de corrupção a partir da apreensão dos mundos morais a 
que remetem. Dessa forma, e contrariando certa tendência da análise sociológica influente, o caminho a ser seguido é menos o de inquirir a sub-socialização de determinadas normas de condução diante do público e da coisa pública, e, mais, o de direcionarmos o nosso foco analítico para os regimes morais (ou "mundos morais") que tais práticas remetem. E essa perspectiva, nós sabemos de há muito, por indicação de um clássico sempre muito atual, só é possível quando nos colocamos o desafio de tentar apreender o sentido atribuído pelos atores àquilo que fazem.

Tomando como ilustração o "Escândalo do Mensalão", procurei apontar o quanto uma sociologia da moral poderia possibilitar uma compreensão mais nuançada das práticas de corrupção no Brasil. Essa sociologia poderia fornecer elementos para uma inquirição mais fundamentada a respeito das bases morais (ou, para sermos mais cuidadosos, das "justificações") mobilizadas pelos atores as práticas de corrupção. Uma tradução imediata dessa assunção é a de que as organizações sociais (coloco sob essa rubrica, aqui, por fins práticos, instituições e órgãos do Estado) são atravessadas por ordens morais diversas. No cotidiano dos espaços institucionais onde se desenrolam as transações identificadas com a rubrica de corruptas existem contradições e enfrentamentos entre mundos e ordens morais diversas. Essas ordens expressam-se não apenas em modos distintos, e não raro contraditórios, de coordenação das ações dos atores, mas também, o que é mais importante, em objetivos e "objetos" diferentes e singulares.

A exposição acima não autoriza, entretanto, certa proposição, também comum entre diversos analistas do mundo político brasileiro, de oposição entre uma "ordem familiar e/ou patrimonial" e a "ordem pública". Trata-se de algo distinto aqui. Mais concretamente, de universos de referências morais que são pragmaticamente mobilizados pelos atores em situações concretas. Ou, nos termos da sociologia moral de Laurent Thévenot (2001), de "ordens de grandeza" diferenciadas.

\section{REFERÊNCIAS}

BECKER, Howard S. Outsiders: estudos de sociologia do desvio. Tradução de: Maria Luzia X. de Borges. Rio de Janeiro: Jorge Zahar, 2008.

BOLTANSKY, Luc. Usos fracos e usos intensos do babitus. In: ENCREVÉ; Pierre, et al. Trabalhar com Bourdieu. Tradução de: Karina Jannini. Rio de Janeiro: Betrando do Brasil, 2005, p. 25-37. 
BOLTANSKY, Luc; CHIAPELLO, Eve. O novo espirito do capitalismo. São Paulo: Martins Fontes, 2009.

BOURDIEU, Pierre. A produção da crença: contribuição para uma economia dos bens simbólicos. Porto Alegre: Zouk, 2006.

. Meditações pascalianas. Tradução de: Sérgio Miceli. Rio de Janeiro: Bertrand Brasil, 2001.

CALDEIRA, Teresa Pires do Rio. Cidade de muros: crime, segregação e cidadania em São Paulo. São Paulo: Ed. 34, 2000.

DE BLIC, Damien; LEMIEUX, Cyril. Le scandale comme épreuve: elements de sociologie pragmatique. Politix, Paris, n. 71, p. 9-38, mai. 2005.

GIDDENS, Anthony. The consequences of modernity. Palo Alto: Stanford University Press, 1993.

GRANOVETTER, Mark. The social construction of corruption. Disponivel em: $<$ http://www.economyandsociety.org > . Acesso em: 15 dez. 2005.

GRUN, Roberto. Guerra cultural e transformações sociais: as eleições presidenciais de 2006 e a "blogsfera". Sociedade e Estado, Brasília, v. 23, n. 3, p. 621-666, set./ dez. 2008.

GUPTA, Akhil. Narratives of corruption: anthropological and fictional accounts of the Idian state. Ethnography, London, v. 6, n. 1, p. 5-34, Mar. 2005.

OLIVEIRA, Luis R. Cardoso. 0 material, o simbólico e o contra-intuitivo: uma trajetória reflexiva. Série Antropologia, Brasília, 2008.

POLANYI, Karl. A grande transformação: as origens da nossa época. São Paulo: Campus, 2000.

SOUSA, Jessé. A ralé brasileira: quem é e como vive. Belo Horizonte: Ed. UFMG, 2009.

THÉVENOT, Laurent. Organized complexity: conventions of coordination and the composition of economic arrangements. European Journal of Social Theory, London, n. 3, p. 405-425, 2001.

THOMPSON, John B. La nouvelle visibilité. Réseaux, Lavoisier, n. 129-30, p. 5987, 2005. 